\title{
Trends in dietary intake in Switzerland, 1999 to 2009
}

\author{
Daisy Abreu', Isabel Cardoso', Jean-Michel Gaspoz ${ }^{2}$, Idris Guessous ${ }^{1,2}$ and \\ Pedro Marques-Vidal ${ }^{1, *}$ \\ ${ }^{1}$ Institute of Social and Preventive Medicine (IUMSP), University of Lausanne, Bâtiment Biopôle 2, Route de la \\ Corniche 10, CH-1010 Lausanne, Switzerland: '2Unit of Population Epidemiology, Geneva University Hospitals, \\ Geneva, Switzerland
}

Submitted 8 May 2012: Final revision received 23 September 2012: Accepted 14 December 2012: First published online 21 February 2013

\begin{abstract}
Objective: To assess nutrition trends of the Geneva population for the period 1999-2009.

Design: Bus Santé Geneva study, which conducts annual health surveys in random samples of the Geneva population. Dietary intake was assessed using a validated FFQ and trends were assessed by linear regression.

Setting: Population-based survey.

Subjects: Data from 9283 participants (50\% women, mean age $51 \cdot 5$ (SD 10.8) years) were analysed.

Results: In both genders total energy intake decreased from 1999 to 2009, by $2.9 \%$ in men and by $6.3 \%$ in women (both trends $P<0.005$ ). Vegetable protein and total carbohydrate intakes, expressed as a percentage of total energy intake, increased in women. MUFA intake increased while SFA, PUFA and alcohol intakes decreased in both genders. Intakes of $\mathrm{Ca}, \mathrm{Fe}$ and carotene decreased in both genders. No changes in fibre, vitamin D and vitamin A intakes were found. Similar findings were obtained after excluding participants with extreme dietary intakes, except that the decreases in SFA, vegetable protein and carbohydrate were no longer significant in women.

Conclusions: Between 1999 and 2009, a small decrease in total energy intake was noted in the Geneva population. Although the decrease in alcohol and SFA intakes is of interest, the decrease in $\mathrm{Ca}$ and Fe intakes may have adverse health effects in the future.
\end{abstract}

In recent years, considerable changes in food consumption and dietary patterns have occurred globally ${ }^{(1)}$. Fat-rich, energy-dense diets or diets with a high content of refined carbohydrates are considered one of the main drivers of the increasing prevalence of chronic diseases such as CVD, diabetes, cancer and obesity ${ }^{(2-4)}$. Hence, major efforts are needed to develop and implement policies to secure a healthy diet ${ }^{(5)}$ and to develop standardized tools to monitor progress towards attainment of such policies $^{(3)}$. For instance, assessing food consumption trends enables agencies to set up and monitor health and nutrition policies and evaluate the extent to which public health messages are perceived and actualized by the population ${ }^{(6)}$.

In a previous study, the trends in dietary intake of the Geneva population were reported for the period 1993 to $2000^{(7)}$. We now report the trends in dietary intake for the period 1999 to 2009 using the same methodology and including more dietary components than before.

\section{Methods}

\section{Sampling}

The sampling methodology of the Bus Santé Geneva study has been reported previously ${ }^{(8)}$. Briefly, Bus Santé Geneva aims to monitor risk factors at the community level. Since 1993, the Bus Santé Geneva study has been conducting annual health examination surveys in independent random samples of the total resident population of the Geneva canton, Switzerland. Participants were identified $^{(9)}$ by means of a standardized procedure using an annual residential list established by local government. This list includes all potential eligible participants aged 34-74 years except persons living illegally in the country. Stratified random sampling was performed on the basis of the list, by gender, within 10-year age strata, proportional to the corresponding population distributions. Two clinics as well as a mobile unit were used to perform the examinations. The survey was conducted throughout the year, from January to December. Participation rates 
during the period 1999-2009 are indicated in Table 1. The Bus Santé Geneva study complied with the Declaration of Helsinki and was approved by the Institutional Ethics Committee of the University of Geneva. All participants gave written informed consent.

An invitation letter was mailed to all potential participants, asking them to indicate the day and time more convenient to come to the mobile unit. In the case of no response, up to seven attempts were made to reach the person by telephone at different times of the day and various days of the week, including Saturday and Sunday. Two more letters were sent when a selected individual could not be reached by telephone. A person who had not been reached after three mailings and seven telephone calls was replaced using the same selection protocol $^{(8)}$. For the period 2005-2008 a smaller number of participants were recruited, as another study was conducted in the Unit of Population Epidemiology with the same amount of resources.

\section{Dietary intake}

Dietary intake was assessed using a self-administered, semi-quantitative FFQ which also included portion size ${ }^{(10,11)}$. This FFQ has been validated in the Geneva population ${ }^{(10-12)}$ and several results have been published previously $^{(8,13)}$. Briefly, the FFQ assesses the dietary intake of the previous 4 weeks and consists of ninety-seven different food items which account for more than $90 \%$ of the intake of energy, protein, fat, carbohydrate, alcohol, cholesterol, vitamin D and retinol, and $85 \%$ of the intake of fibre, carotene and Fe. For each item, consumption frequencies ranging from 'less than once during the last 4 weeks' to ' 2 or more times per day' were provided, and the participants also indicated the average serving size (smaller, equal or bigger) compared with a reference size. Each participant brought along her/his filled-in FFQ, which was checked for completion by trained interviewers on the day of the visit. Hence, the response rate for the FFQ was $100 \%$.

The FFQ data were then converted into nutrients, which were used in the present analysis. The conversion used a single food composition table, which remained identical throughout the study. Total intake of vitamin A was computed in retinol equivalents (RE) according to the formula: $\mathrm{RE}=$ retinol intake $+(\beta \text {-carotene intake/12 })^{(14)}$. Under-reporting was considered if the total energy intake was $<3556 \mathrm{~kJ} / \mathrm{d}(<850 \mathrm{kcal} / \mathrm{d})$.

\section{Data collected}

Participants were asked to fast for at least $8 \mathrm{~h}$. Interviews and examinations were performed from Monday to Friday, between 07.30 and 10.30 hours. On the day of the visit, participants brought back the completed FFQ and a self-administered standardized questionnaire covering lifestyle factors, reproductive history and cardiovascular risk factors. Smoking status was grouped into never, former and current. Age was categorized into age groups of 34-44, 45-54, 55-64 and 65-74 years. Self-reported data on educational level (low/high) were collected; low educational level was defined as primary school and high educational level as secondary/tertiary. Physical activity was assessed using a validated questionnaire ${ }^{(15)}$. Participants were considered as sedentary if they spent less than $10 \%$ of their daily energy on activities with intensity four times their (sex-, age-, height- and weight-adjusted) BMR, calculated using WHO formulas ${ }^{(16)}$. More details on the examination procedure are available elsewhere ${ }^{(8)}$.

\section{Statistical analysis}

Statistical analyses were performed with the Stata statistical software package version 12. Participants without data for education ( $n$ 37) were excluded from the analyses. Statistical analysis was conducted in two steps: (i) using the whole sample and (ii) excluding participants with extreme values for energy intake ( $<3556$ and $>18828 \mathrm{~kJ} / \mathrm{d}(<850$ and $>4500 \mathrm{kcal} / \mathrm{d}$ )) as recommended ${ }^{(17)}$. For each nutrient (absolute value or expressed as a percentage of total energy intake), descriptive results were expressed as mean and standard deviation. Similar to previous studies, trends in dietary intake were assessed separately for each gender by linear regression using survey year as the independent variable. As the distribution of participants throughout the year was not identical between years, it was decided to adjust on year quarter as previously ${ }^{(7)}$. Multivariate analysis was conducted adjusting for age, smoking status, educational level, sedentariness (yes/no) and quarter. For nutrients, a further adjustment on total energy intake was also performed. As the FFQ collected data on the 4 weeks preceding the examination, a second analysis was conducted after subtracting $28 \mathrm{~d}$ from the date of examination, so that the year corresponded to the period of dietary consumption. Hence, a participant examined on 15 January 2005 would be considered as providing dietary data for 2004. Statistical significance was considered as $P<0 \cdot 05$.

\section{Results}

\section{Descriptive data}

Data from 9283 participants ( $50 \%$ men), mean age 51.5 (SD 10.8) years (range 34-74 years), were analysed. Their main characteristics according to year of survey are summarized in Table 1 . No significant differences were found regarding age, BMI and BMI categories, while the prevalence of current smokers decreased and the prevalence of former smokers increased from 1999 to 2009.

\section{Trends in nutrient intake}

The trends in dietary intake for the period 1999-2009 according to gender are summarized in Table 2 . Between 1999 and 2009, total energy intake decreased by $2 \cdot 9 \%$ in men and by $6.3 \%$ in women. Vegetable protein intake as 
Table 1 Characteristics of the participants in the different surveys of the Bus Sante Geneva study, 1999 to 2009

\begin{tabular}{|c|c|c|c|c|c|c|c|c|c|c|c|c|}
\hline & 1999 & 2000 & 2001 & 2002 & 2003 & 2004 & 2005 & 2006 & 2007 & 2008 & 2009 & $P$ value \\
\hline Sample size & 1157 & 1144 & 1235 & 1258 & 1232 & 1040 & 215 & 257 & 262 & 455 & 1028 & \\
\hline Participation rate (\%) & $57 \cdot 7$ & $55 \cdot 9$ & $62 \cdot 4$ & $61 \cdot 7$ & $63 \cdot 0$ & $63 \cdot 2$ & $56 \cdot 0$ & $58 \cdot 1$ & 54.9 & $48 \cdot 5$ & $54 \cdot 3$ & \\
\hline Women (\%) & $48 \cdot 0$ & $51 \cdot 2$ & $48 \cdot 8$ & $49 \cdot 2$ & $50 \cdot 2$ & $51 \cdot 1$ & $54 \cdot 4$ & $48 \cdot 6$ & $48 \cdot 9$ & $50 \cdot 3$ & $52 \cdot 7$ & 0.52 \\
\hline \multicolumn{13}{|l|}{ Age (years) } \\
\hline Mean & $51 \cdot 0$ & $51 \cdot 4$ & $52 \cdot 4$ & $51 \cdot 3$ & $51 \cdot 4$ & $50 \cdot 9$ & $51 \cdot 8$ & $51 \cdot 6$ & $51 \cdot 8$ & $51 \cdot 7$ & $51 \cdot 7$ & 0.09 \\
\hline SD & $10 \cdot 6$ & $10 \cdot 3$ & $11 \cdot 4$ & $10 \cdot 6$ & $10 \cdot 9$ & $10 \cdot 8$ & $11 \cdot 3$ & $11 \cdot 1$ & $11 \cdot 2$ & $11 \cdot 2$ & $10 \cdot 8$ & \\
\hline \multicolumn{13}{|l|}{ Education (\%) } \\
\hline Low & $32 \cdot 2$ & $31 \cdot 4$ & $32 \cdot 3$ & $31 \cdot 7$ & $35 \cdot 5$ & $38 \cdot 0$ & $28 \cdot 8$ & $37 \cdot 7$ & $27 \cdot 1$ & $28 \cdot 8$ & $31 \cdot 5$ & $<0.001$ \\
\hline High & $67 \cdot 9$ & $68 \cdot 6$ & $67 \cdot 7$ & $68 \cdot 3$ & $64 \cdot 5$ & $62 \cdot 0$ & $71 \cdot 2$ & $62 \cdot 3$ & $72 \cdot 9$ & $71 \cdot 2$ & $68 \cdot 5$ & \\
\hline \multicolumn{13}{|l|}{ Smoking status (\%) } \\
\hline Never & $45 \cdot 4$ & $45 \cdot 4$ & $43 \cdot 7$ & $46 \cdot 2$ & $42 \cdot 4$ & $47 \cdot 2$ & $44 \cdot 7$ & $43 \cdot 2$ & $49 \cdot 2$ & $44 \cdot 8$ & $44 \cdot 8$ & \\
\hline Former & $26 \cdot 8$ & $28 \cdot 6$ & $29 \cdot 6$ & $27 \cdot 9$ & $31 \cdot 3$ & $27 \cdot 9$ & $33 \cdot 0$ & 31.9 & $29 \cdot 8$ & $33 \cdot 0$ & $33 \cdot 5$ & 0.02 \\
\hline Current & $27 \cdot 8$ & $26 \cdot 0$ & $26 \cdot 6$ & $25 \cdot 9$ & $26 \cdot 3$ & $24 \cdot 9$ & $22 \cdot 3$ & $24 \cdot 9$ & $21 \cdot 0$ & $22 \cdot 2$ & $21 \cdot 7$ & \\
\hline Sedentary (\%) & $63 \cdot 0$ & $61 \cdot 8$ & $65 \cdot 1$ & $64 \cdot 2$ & $64 \cdot 4$ & $64 \cdot 2$ & $67 \cdot 9$ & $65 \cdot 4$ & $58 \cdot 0$ & $65 \cdot 1$ & $62 \cdot 4$ & $0 \cdot 41$ \\
\hline$<3556 \mathrm{~kJ} / \mathrm{d}(<850 \mathrm{kcal} / \mathrm{d})(\%)$ & $2 \cdot 4$ & $2 \cdot 5$ & $2 \cdot 1$ & 1.9 & $1 \cdot 6$ & $1 \cdot 9$ & $3 \cdot 7$ & $1 \cdot 6$ & $1 \cdot 2$ & $2 \cdot 2$ & $3 \cdot 0$ & $0 \cdot 35$ \\
\hline
\end{tabular}

Results are expressed as percentages or mean and standard deviation. Statistical analysis by the $\chi^{2}$ test or ANOVA.

Table 2 Dietary intake of the Geneva population, 1999-2009, according to gender, all participants ( $n$ 9283)

\begin{tabular}{|c|c|c|c|c|c|c|c|c|c|c|c|c|}
\hline & \multicolumn{6}{|c|}{ Men ( $n$ 4622) } & \multicolumn{6}{|c|}{ Women ( $n$ 4641) } \\
\hline & \multicolumn{2}{|c|}{1999} & \multicolumn{2}{|c|}{2009} & \multicolumn{2}{|c|}{$P$ value for trend } & \multicolumn{2}{|c|}{1999} & \multicolumn{2}{|c|}{2009} & \multicolumn{2}{|c|}{$P$ value for trend } \\
\hline & Mean & $\mathrm{SD}$ & Mean & SD & Crude* & Adj. ${ }^{+}$ & Mean & SD & Mean & SD & Crude* & Adj.t \\
\hline Total energy $(\mathrm{kJ} / \mathrm{d})$ & 9301 & 3230 & 9037 & 3251 & 0.004 & 0.006 & 7648 & 2741 & 7171 & 2607 & $<0.001$ & $<0.001$ \\
\hline Total energy (kcal/d) & 2223 & 772 & 2160 & 777 & 0.004 & 0.006 & 1828 & 655 & 1714 & 623 & $<0.001$ & $<0.001$ \\
\hline \multicolumn{13}{|c|}{ Dietary intake ( $\%$ of total energy) } \\
\hline Protein & $15 \cdot 5$ & $2 \cdot 9$ & $15 \cdot 5$ & $3 \cdot 3$ & 0.97 & 0.95 & $15 \cdot 7$ & $3 \cdot 2$ & $15 \cdot 7$ & $3 \cdot 3$ & 0.55 & 0.60 \\
\hline Vegetable protein & $4 \cdot 6$ & $1 \cdot 1$ & $4 \cdot 6$ & $1 \cdot 2$ & 0.39 & 0.63 & $4 \cdot 8$ & $1 \cdot 2$ & 4.9 & $1 \cdot 3$ & 0.04 & 0.04 \\
\hline Animal protein & $10 \cdot 9$ & $3 \cdot 2$ & $10 \cdot 8$ & $3 \cdot 7$ & $0 \cdot 76$ & $0 \cdot 84$ & $10 \cdot 9$ & $3 \cdot 6$ & $10 \cdot 8$ & $3 \cdot 8$ & 0.23 & $0 \cdot 26$ \\
\hline Carbohydrate & $44 \cdot 1$ & $8 \cdot 3$ & $44 \cdot 9$ & $9 \cdot 0$ & 0.02 & 0.05 & $45 \cdot 9$ & $8 \cdot 4$ & $46 \cdot 4$ & $9 \cdot 4$ & 0.04 & 0.03 \\
\hline Monosaccharides & $18 \cdot 9$ & $6 \cdot 8$ & $20 \cdot 2$ & $7 \cdot 6$ & $<0.001$ & $<0.001$ & $22 \cdot 3$ & $7 \cdot 9$ & $22 \cdot 7$ & $8 \cdot 5$ & 0.09 & $0 \cdot 11$ \\
\hline Polysaccharides & $25 \cdot 2$ & $7 \cdot 2$ & $24 \cdot \overline{5}$ & $7 \cdot 9$ & 0.28 & $0 \cdot 18$ & $23 \cdot 5$ & $7 \cdot 4$ & $23 \cdot 6$ & $8 \cdot 1$ & 0.50 & 0.37 \\
\hline Total fat & $34 \cdot 1$ & $6 \cdot 5$ & $33 \cdot 8$ & $6 \cdot 8$ & 0.98 & 0.98 & $34 \cdot 7$ & $6 \cdot 3$ & $35 \cdot 0$ & $7 \cdot 3$ & 0.58 & 0.51 \\
\hline SFA & $13 \cdot 1$ & $3 \cdot 3$ & $12 \cdot 5$ & $3 \cdot 4$ & 0.008 & 0.01 & $12 \cdot 3$ & $3 \cdot 1$ & $12 \cdot 1$ & $3 \cdot 2$ & 0.02 & 0.02 \\
\hline MUFA & $13 \cdot 2$ & $3 \cdot 2$ & $13 \cdot 6$ & $3 \cdot 4$ & 0.001 & 0.001 & $14 \cdot 0$ & 3.5 & $14 \cdot 6$ & $4 \cdot 3$ & 0.04 & 0.06 \\
\hline PUFA & $5 \cdot 2$ & $1 \cdot 8$ & 4.9 & $1 \cdot 6$ & 0.002 & 0.002 & $5 \cdot 4$ & $1 \cdot 8$ & $5 \cdot 1$ & $1 \cdot 6$ & $<0.001$ & $<0.001$ \\
\hline Alcohol & $6 \cdot 2$ & $6 \cdot 4$ & $5 \cdot 9$ & $6 \cdot 3$ & 0.001 & 0.008 & $3 \cdot 6$ & $4 \cdot 6$ & $2 \cdot 9$ & $3 \cdot 8$ & 0.005 & 0.002 \\
\hline \multicolumn{13}{|l|}{ Daily nutrient intake } \\
\hline Fibre $(g)$ & $16 \cdot 8$ & $9 \cdot 8$ & $16 \cdot 7$ & $9 \cdot 8$ & 0.23 & 0.64 & $17 \cdot 2$ & $10 \cdot 1$ & $16 \cdot 2$ & $8 \cdot 4$ & $0 \cdot 10$ & $0 \cdot 16$ \\
\hline Cholesterol (mg) & 367 & 176 & 350 & 175 & 0.03 & 0.91 & 288 & 125 & 278 & 134 & 0.01 & 0.60 \\
\hline $\mathrm{Ca}(\mathrm{mg})$ & 1231 & 677 & 1093 & 585 & $<0.001$ & $<0.001$ & 1051 & 519 & 936 & 481 & $<0.001$ & 0.006 \\
\hline $\mathrm{Fe}(\mathrm{mg})$ & $12 \cdot 4$ & 4.5 & $12 \cdot 0$ & 4.5 & 0.001 & 0.051 & $10 \cdot 7$ & $4 \cdot 2$ & $9 \cdot 8$ & $3 \cdot 6$ & $<0.001$ & 0.02 \\
\hline Retinol $(\mu \mathrm{g})$ & $633 \cdot 8$ & $578 \cdot 2$ & $550 \cdot 9$ & $559 \cdot 7$ & 0.03 & 0.22 & $480 \cdot 0$ & $506 \cdot 7$ & $433 \cdot 3$ & $486 \cdot 7$ & $0 \cdot 19$ & 0.92 \\
\hline Carotene $(\mu \mathrm{g})$ & 3397 & 2169 & 3891 & 2927 & 0.001 & $<0.001$ & 4186 & 4010 & 4794 & 4050 & $<0.001$ & $<0.001$ \\
\hline Vitamin A (RE) & 917 & 627 & 875 & 631 & 0.40 & 0.68 & 829 & 620 & 833 & 593 & 0.38 & 0.006 \\
\hline Vitamin D $(\mu \mathrm{g})$ & $2 \cdot 96$ & $2 \cdot 64$ & $2 \cdot 93$ & $2 \cdot 69$ & $0 \cdot 10$ & 0.54 & $2 \cdot 67$ & $1 \cdot 80$ & $2 \cdot 65$ & $2 \cdot 13$ & 0.48 & $0 \cdot 38$ \\
\hline
\end{tabular}

$R E$, retinol equivalents.

Trends were assessed by linear regression: *unadjusted; tadjusted for age, smoking status, educational level, sedentariness and quarter. For nutrients, a further adjustment on total energy intake was also performed.

well as total carbohydrate intake, expressed as a percentage of total energy intake, increased in women. MUFA intake increased while SFA, PUFA and alcohol intakes decreased in both genders. A further increase in monosaccharide intake was observed in men only. Daily intakes of cholesterol, $\mathrm{Ca}$ and Fe decreased, while the intake of carotene increased in both genders. A decrease in retinol intake was also found, but only among men. Conversely, no changes in fibre, vitamin A and vitamin D intakes were found. Similar findings were obtained after multivariate adjustment (Table 2), except that the increase in MUFA became borderline significant in women $(P=0 \cdot 06)$, the decrease in
Fe became borderline significant in men $(P=0.051)$ and the decrease in cholesterol intake was no longer significant in both genders (Table 2).

Similar findings were obtained when participants with extreme dietary intakes $(<3556$ and $>18828 \mathrm{~kJ} / \mathrm{d}(<850$ and $>4500 \mathrm{kcal} / \mathrm{d}$ )) were excluded ( $n$ 271), except that the decrease in SFA, as well as the increase in vegetable protein and carbohydrate, were no longer significant in women. Multivariate adjustment resulted in similar findings, except that the increase in total carbohydrate was no longer significant in men and the decrease in cholesterol was no longer significant in both genders (Table 3). Finally, the 
Table 3 Dietary intake of the Geneva population, 1999-2009, according to gender, excluding participants with extreme dietary intakes ( $n$ 9012)

\begin{tabular}{|c|c|c|c|c|c|c|c|c|c|c|c|c|}
\hline & \multicolumn{6}{|c|}{ Men (n 4535) } & \multicolumn{6}{|c|}{ Women ( $n$ 4477) } \\
\hline & \multicolumn{2}{|c|}{1999} & \multicolumn{2}{|c|}{2009} & \multicolumn{2}{|c|}{$P$ value for trend } & \multicolumn{2}{|c|}{1999} & \multicolumn{2}{|c|}{2009} & \multicolumn{2}{|c|}{$P$ value for trend } \\
\hline & Mean & SD & Mean & SD & Crude* & Adj.t & Mean & SD & Mean & SD & Crude* & Adj.t \\
\hline Total energy (kJ/d) & 9238 & 2791 & 8970 & 2912 & 0.001 & 0.001 & 7791 & 2582 & 7372 & 2406 & $<0.001$ & $<0.001$ \\
\hline Total energy $(\mathrm{kcal} / \mathrm{d})$ & 2208 & 667 & 2144 & 696 & 0.001 & 0.001 & 1862 & 617 & 1762 & 575 & $<0.001$ & $<0.001$ \\
\hline \multicolumn{13}{|c|}{ Dietary intake (\% of total energy) } \\
\hline Protein & $15 \cdot 5$ & $2 \cdot 8$ & $15 \cdot 4$ & $3 \cdot 3$ & $0 \cdot 88$ & 0.86 & $15 \cdot 6$ & $3 \cdot 1$ & $15 \cdot 6$ & $3 \cdot 3$ & 0.92 & 0.99 \\
\hline Vegetable protein & $4 \cdot 6$ & $1 \cdot 1$ & $4 \cdot 6$ & $1 \cdot 2$ & $0 \cdot 36$ & $0 \cdot 61$ & $4 \cdot 8$ & $1 \cdot 2$ & $4 \cdot 9$ & $1 \cdot 3$ & 0.07 & 0.07 \\
\hline Animal protein & $10 \cdot 9$ & $3 \cdot 2$ & $10 \cdot 8$ & $3 \cdot 7$ & $0 \cdot 66$ & $0 \cdot 76$ & $10 \cdot 8$ & $3 \cdot 5$ & $10 \cdot 7$ & $3 \cdot 8$ & 0.49 & 0.57 \\
\hline Carbohydrates & $44 \cdot 2$ & $8 \cdot 3$ & $44 \cdot 9$ & $9 \cdot 0$ & $0 \cdot 03$ & 0.08 & $46 \cdot 2$ & $8 \cdot 3$ & $46 \cdot 4$ & $9 \cdot 3$ & 0.23 & $0 \cdot 18$ \\
\hline Monosaccharides & $18 \cdot 9$ & $6 \cdot 8$ & $20 \cdot 2$ & $7 \cdot 5$ & $<0.001$ & $<0.001$ & $22 \cdot 4$ & $7 \cdot 9$ & $22 \cdot 6$ & $8 \cdot 2$ & $0 \cdot 26$ & $0 \cdot 28$ \\
\hline Polysacharides & $25 \cdot 2$ & $7 \cdot 2$ & $24 \cdot 6$ & $7 \cdot 9$ & 0.38 & $0 \cdot 24$ & $23 \cdot 6$ & $7 \cdot 4$ & $23 \cdot 7$ & $7 \cdot 9$ & $0 \cdot 83$ & $0 \cdot 68$ \\
\hline Total fat & $34 \cdot 1$ & $6 \cdot 5$ & $33 \cdot 8$ & $6 \cdot 8$ & $0 \cdot 87$ & 0.86 & $34 \cdot 6$ & $6 \cdot 3$ & $35 \cdot 1$ & $7 \cdot 3$ & 0.87 & 0.95 \\
\hline SFA & $13 \cdot 1$ & $3 \cdot 3$ & $12 \cdot 5$ & $3 \cdot 4$ & 0.01 & 0.01 & $12 \cdot 3$ & $3 \cdot 1$ & $12 \cdot 2$ & $3 \cdot 2$ & 0.07 & 0.07 \\
\hline MUFA & $13 \cdot 2$ & $3 \cdot 2$ & $13 \cdot 6$ & $3 \cdot 4$ & $<0.001$ & $<0.001$ & $13 \cdot 9$ & $3 \cdot 4$ & $14 \cdot 7$ & $4 \cdot 3$ & 0.006 & 0.01 \\
\hline PUFA & $5 \cdot 1$ & $1 \cdot 8$ & 4.9 & $1 \cdot 6$ & 0.003 & 0.002 & $5 \cdot 4$ & $1 \cdot 8$ & $5 \cdot 1$ & $1 \cdot 6$ & $<0.001$ & $<0.001$ \\
\hline Alcohol & $6 \cdot 2$ & $6 \cdot 3$ & $5 \cdot 9$ & $6 \cdot 3$ & 0.002 & 0.01 & $3 \cdot 6$ & $4 \cdot 6$ & $2 \cdot 9$ & $3 \cdot 8$ & 0.01 & 0.005 \\
\hline \multicolumn{13}{|l|}{ Daily nutrient intake } \\
\hline Fibre (g) & $16 \cdot 5$ & $8 \cdot 8$ & $16 \cdot 7$ & $9 \cdot 6$ & $0 \cdot 21$ & $0 \cdot 60$ & $17 \cdot 5$ & $10 \cdot 0$ & $16 \cdot 7$ & $8 \cdot 2$ & 0.09 & $0 \cdot 16$ \\
\hline Cholesterol (mg) & 367 & 170 & 345 & 142 & 0.001 & 0.23 & 293 & 123 & 285 & 130 & 0.01 & 0.56 \\
\hline $\mathrm{Ca}(\mathrm{mg})$ & 1220 & 625 & 1087 & 563 & $<0.001$ & $<0.001$ & 1067 & 516 & 960 & 478 & $<0.001$ & 0.01 \\
\hline $\mathrm{Fe}(\mathrm{mg})$ & $12 \cdot 4$ & $4 \cdot 0$ & $11 \cdot 9$ & $4 \cdot 1$ & $<0.001$ & 0.03 & $10 \cdot 9$ & $4 \cdot 1$ & $10 \cdot 1$ & $3 \cdot 3$ & $<0.001$ & 0.02 \\
\hline Retinol $(\mu \mathrm{g})$ & 630 & 566 & 547 & 553 & 0.02 & $0 \cdot 22$ & 488 & 509 & 441 & 483 & 0.22 & 0.96 \\
\hline Carotene $(\mu \mathrm{g})$ & 3394 & 2130 & 3863 & 2873 & 0.003 & $<0.001$ & 4270 & 4039 & 4906 & 4037 & $<0.001$ & $<0.001$ \\
\hline Vitamin A (RE) & 913 & 606 & 867 & 616 & $0 \cdot 27$ & $0 \cdot 84$ & 844 & 619 & 850 & 584 & $0 \cdot 36$ & 0.006 \\
\hline Vitamin D $(\mu \mathrm{g})$ & $2 \cdot 90$ & $2 \cdot 54$ & $2 \cdot 85$ & $2 \cdot 09$ & 0.05 & $0 \cdot 31$ & $2 \cdot 71$ & $1 \cdot 79$ & $2 \cdot 74$ & $2 \cdot 15$ & 0.57 & 0.33 \\
\hline
\end{tabular}

$R E$, retinol equivalents.

Trends were assessed by linear regression: *unadjusted; tadjusted for age, smoking status, educational level, sedentariness and quarter. For nutrients, a further adjustment on total energy intake was also performed.

analysis taking into account the period of dietary collection (i.e. subtracting $28 \mathrm{~d}$ from the examination date) led to similar conclusions (see Supplementary Materials, supplementary tables 1 and 2).

\section{Discussion}

There is little information regarding dietary trends in Switzerland, a country characterized by relatively low obesity levels ${ }^{(18)}$ and a low mortality from $\operatorname{CVD}^{(19,20)}$. A previous study ${ }^{(21)}$ provided data for a longer period (1961-2007), but that study relied on data from the FAO food balance sheets (http://www.fao.org) and not on individually assessed data. The present study provides insight into the dietary intake of the Geneva population for the period 1999 to 2009 using a standardized methodology. Our results indicate a slight and significant decrease in total energy intake, decreases in the percentage of total energy intake derived from SFA, PUFA and alcohol, and increases in the percentage of total energy intake derived from carbohydrate and MUFA. Regarding nutrients, significant decreases in the intakes of $\mathrm{Ca}$ and Fe were found.

The reasons for such changes are difficult to identify and can only be speculated. For instance, most changes persisted after multivariate adjustment for age, education, physical activity and smoking, thus suggesting that societal changes do not impact dietary changes significantly. A more likely explanation would be changes in the overall provision or personal choice of foods, as has been demonstrated in other countries ${ }^{(22)}$. For instance, previous studies conducted in Geneva showed that food-borne events such as 'mad cow disease' impacted food intake, but that the magnitude of the effect varied according to gender $^{(14,23)}$. Overall, more studies are needed to better assess the societal, economic and other factors responsible for the changes in dietary intake in Geneva.

Total energy intake decreased in both genders. These findings confirm the results of the previous study period ${ }^{(8)}$ where a significant decline in total energy intake was found among men but not among women. These findings are also partly in agreement with a prior study ${ }^{(21)}$ which showed no significant increase in total energy availability for the Swiss population. The most likely reason for this decline in total energy intake is a decrease in total energy expenditure, induced by a decrease in physically demanding activities and an increase in sedentary office work. Indeed, and in agreement with a previous study ${ }^{(7)}$, mean BMI did not change throughout the study period, suggesting that this decrease in total energy intake is paralleled by an equivalent decrease in physical activity. Still, other reasons cannot be ruled out, such as an increased underestimation of dietary intake ${ }^{(24)}$, and it would be of interest to confirm these findings in other population-based surveys. 


\section{Major nutrients}

A favourable change in fat intake occurred: the percentage of energy from SFA decreased while that from MUFA increased. Similar trends have also been reported in the US population by the National Health Interview Survey, conducted between 1987 and 1992 ${ }^{(25)}$. The decrease in SFA intake might be related to an augmenting awareness about reducing fat and cholesterol intakes and improving $\operatorname{diet}^{(6)}$. Conversely, the increase in MUFA intake might be attributable to the increase in sunflower oil and olive oil availability ${ }^{(21)}$. Still, in 2009, mean total fat intake represented over $33 \%$ of total energy intake, a value higher than recommended ${ }^{(26)}$. Hence, although the changes in fat quality are of interest, future efforts should be directed at decreasing the percentage of total energy intake derived from fat.

An increase in carbohydrate intake was found, this increase being more pronounced and restricted to monosaccharides in men. This increase is in agreement with the observed augmentation in sugar and sweeteners availability in Switzerland ${ }^{(21)}$. The increase in monosaccharide intake among men only might be related to an increased consumption of sugar or sugar-containing drinks among boys ${ }^{(27,28)}$, which would be maintained in adulthood $^{(29,30)}$.

No changes were found regarding total protein intake, a finding also reported elsewhere ${ }^{(31)}$. These findings are not supported by the official data ${ }^{(32)}$, which showed an increase in beef consumption of $10 \%$ and in poultry consumption of $19 \%$ in 2009 relative to $2000 / 2002$, and also by a previous study ${ }^{(14)}$ which showed a slow increase in meat and beef consumption in women between 1993 and 2000. However, a decrease in beef consumption was found in men. Although a possible geographical bias might be present, with the Geneva population consuming less meat than the rest of the country, there are currently no data available regarding geographical patterns of food consumption for Switzerland and future studies are needed to better assess this point.

\section{Otber nutrients}

A decrease in alcohol intake was observed, a finding in agreement with a previous study ${ }^{(33)}$ and also confirmed by the Swiss federal office of alcohols, which reported a decrease in total per capita alcohol consumption from $9 \cdot 21$ /year in 1999 to 8.71 /year in $2009^{(34)}$. This decrease can partly be explained by the increasing cost of alcoholic beverages $^{(35)}$ and also by a special tax on alcopops introduced in $2004^{(34)}$. Still, an increase in alcohol consumption has been reported in younger age groups ${ }^{(36)}$, so it would be of interest to monitor if this increase in younger persons is maintained as they get older.

Ca intake decreased considerably in both genders between 1999 and 2009, a finding in contradiction with dairy production. For instance, between 2000 and 2010, cheese production increased by $7 \cdot 8 \%$ in Switzerland ${ }^{(32)}$ and total milk production increased from 3.05 million tonnes in 1990 to 3.44 million tonnes in $2010^{(37)}$. As suggested previously, a possible explanation might be the predominantly urban setting of the Geneva population, as it has been shown that urban subjects consume less Ca than their rural counterparts ${ }^{(38,39)}$. Still, our data stress the need for promoting the consumption of Ca-rich foods, as it has been suggested that over half of the Swiss population does not get the daily amount of $\mathrm{Ca}$ recommended for the prevention of osteoporosis ${ }^{(40)}$.

As for $\mathrm{Ca}$, a significant decrease in Fe intake was found for both genders. The reasons for such a decrease might be related to changes in meat sources, namely the increase of poultry relative to beef ${ }^{(21)}$. This unfavourable trend might lead to an increase in the prevalence of Fe-deficiency anaemia in Switzerland, estimated at 9.7\% of pregnant ${ }^{(41)}$ and $12 \cdot 0 \%$ of non-pregnant women of reproductive $\operatorname{age}^{(42)}$.

\section{Study limitations}

The present study has several limitations worth noting. First, data were collected using an FFQ, which might provide an incomplete account of all foods consumed. Still, FFQ are commonly used in epidemiological studies because of their low cost and ease of use ${ }^{(43)}$ and it has been shown that FFQ are appropriate tools for ranking individuals according to their food and nutrient intakes (e.g. as shown by a study on salt intake that compared $24 \mathrm{~h}$ urine collection with salt intake estimated by FFQ, in which similar estimations were obtained by both methods ${ }^{(12)}$ ). Also, it is possible that some participants might have (un)voluntarily under-reported their true habitual food intake, resulting in energy intakes lower than required for long-term energy balance ${ }^{(44)}$. Still, the percentage of underreporters was low and excluding participants with extreme values led to similar conclusions.

Dietary changes over time in populations are usually gradual in response to food availability, economic pressure or public health campaigns ${ }^{(14)}$ and it is possible that some changes in dietary intake might have been missed by this FFQ, such as the introduction of novel foods. Still, a change in the FFQ to account for these possible changes would be impractical, as it would require validation and the results might not be fully comparable with the previous instrument. Hence, and despite the existence of other validated FFQ for the French-speaking part of Switzerland ${ }^{(43)}$, it was decided to use the same instrument throughout the study period. Two nationwide healthy diet campaigns have occurred in Switzerland: one in 2006 ('Marchez et mangez malin' - 'Walk and eat smart') and another in 2007 ('Poids corporel sain' - 'Healthy body weight'). Although their nationwide impact on dietary intake has never been assessed, comparison between 2004-05 and 2008-09 showed no significant differences in dietary intake, with the exception of a statistically significant but nutritionally minor decrease of $40 \mathrm{mg} / \mathrm{d}$ in Ca intake (data not shown). Hence, 
it is unlikely that the changes observed in the present study can be attributed to public health campaigns; another possibility is that the changes induced by these campaigns are too small to be observed with our sample size. In the years 2005-2008 the annual average number of participants was lower than in other years because another cohort study was conducted relying on the same resources. Still, the study protocol and procedures remained identical and comparison of the main characteristics of the participants in the 2005-2008 surveys with those from the adjacent years (2004 and 2009) showed no major difference (data not shown). A single food composition database was used throughout the study. Although this methodology precludes the insertion of changes in food composition, still it facilitates the analysis as the changes observed cannot be attributable to a change in the food composition table. Further, changes in food composition might occur progressively (i.e. the replacement of one type of margarine by another with both types being present simultaneously in supermarkets) and no standard methodology has been proposed to account for this phenomenon. Although our semi-quantitative FFQ included three portion sizes, it is possible that some bias might arise due to participants over- or under-estimating their portions, but the magnitude of the bias cannot be established. Finally, it is currently unknown if the results observed in this mainly urban population also extend to the Swiss population. Still, and to our knowledge, the Bus Santé Geneva study is the only Swiss survey that regularly collects dietary data using population-based surveys, and other studies are urgently needed to confirm these findings. The main strengths of the study are the fact that a similar methodology was used to assess dietary intake, the long study period (11 years) and the use of representative samples of the Geneva population.

\section{Conclusion}

Between 1999 and 2009, a small decrease in total energy intake was noted in the Geneva population. Although the decrease in alcohol, SFA and cholesterol intakes is of interest, the decrease in $\mathrm{Ca}$ and $\mathrm{Fe}$ intakes may have adverse health effects in the future.

\section{Acknowledgements}

Sources of funding: The Bus Santé study is funded by the University Hospitals of Geneva and the General Directorate of Health, Canton of Geneva, Switzerland. Conflict of interest: The authors report no conflict of interest. Authors' contributions: D.A. conducted most of the statistical analyses and wrote most of the article; P.M.-V. conducted part of the statistical analysis and wrote part of the article; I.C. managed the data and conducted the initial statistical analyses; J.-M.G. revised the article for important intellectual content; I.G. collected the data and revised the article for important intellectual content. P.M.-V. had full access to the data and is the guarantor of the study. All authors have reviewed and approved the final version. Acknowledgment: The authors would like to acknowledge the work of the Bus Santé study collaborators, and particularly of Jean-Marc Theler for his precious help.

\section{Supplementary Materials}

For Supplementary Materials for this article, please visit http://dx.doi.org/10.1017/S1368980013000207

\section{References}

1. Schmidhuber J \& Shetty P (2005) The nutrition transition to 2030. Why developing countries are likely to bear the major burden. Food Econ Acta Agric Scand Sect C 2, 150-166.

2. World Health Organization \& Food and Agriculture Organization of the United Nations (2002) Diet, Nutrition and the Prevention of Chronic Diseases. Report of a Joint WHO/FAO Expert Consultation. WHO Technical Report Series no. 916, p. 149. Geneva: WHO

3. Yach D, Hawkes C, Epping-Jordan JE et al. (2003) The World Health Organization's framework convention on tobacco control: implications for global epidemics of food-related deaths and disease. J Public Health Policy 24, 274-290.

4. Kopelman PG (2000) Obesity as a medical problem. Nature 404, 635-643.

5. Lock K, Smith RD, Dangour AD et al. (2010) Health, agricultural, and economic effects of adoption of healthy diet recommendations. Lancet 376, 1699-1709.

6. Perrin AE, Simon C, Hedelin G et al. (2002) Ten-year trends of dietary intake in a middle-aged French population: relationship with educational level. Eur J Clin Nutr 56, 393-401.

7. Galobardes B, Costanza MC, Bernstein MS et al. (2003) Trends in risk factors for the major 'lifestyle-related diseases' in Geneva, Switzerland, 1993-2000. Ann Epidemiol 13, 537-540.

8. Morabia A, Bernstein M, Heritier S et al. (1997) Communitybased surveillance of cardiovascular risk factors in Geneva: methods, resulting distributions, and comparisons with other populations. Prev Med 26, 311-319.

9. Wolff H, Gaspoz JM \& Guessous I (2011) Health care renunciation for economic reasons in Switzerland. Swiss Med Wkly 141, w13165.

10. Morabia A, Bernstein M, Kumanyika S et al. (1994) Development and validation of a semi-quantitative food questionnaire based on a population survey. Soz Praventivmed 39, 345-369.

11. Bernstein L, Huot I \& Morabia A (1995) Amélioration des performances d'un questionnaire alimentaire semiquantitatif comparé à un rappel des 24 heures. Sante Publique 7, 403-413.

12. Beer-Borst S, Costanza MC, Pechere-Bertschi A et al. (2009) Twelve-year trends and correlates of dietary salt intakes for the general adult population of Geneva, Switzerland. Eur J Clin Nutr 63, 155-164.

13. Galobardes B, Morabia A \& Bernstein MS (2001) Diet and socioeconomic position: does the use of different indicators matter? Int J Epidemiol 30, 334-340.

14. Sorenson AW, Delhumeau C, Bernstein MS et al. (2003) Impact of 'mad cow disease' publicity on trends in meat and total vitamin A consumption in Geneva between 1993 and 2000. Eur J Clin Nutr 57, 177-185. 
15. Bernstein M, Sloutskis D, Kumanyika S et al. (1998) Data-based approach for developing a physical activity frequency questionnaire. Am J Epidemiol 147, 147-154.

16. World Health Organization, Food and Agriculture Organization of the United Nations \& United Nations University (1986) Energy and Protein Requirements: Report of a Joint FAO/WHO/UNU Expert Consultation. Technical Report Series no. 724, 1st ed. Geneva: WHO.

17. Iqbal R, Ajayan K, Bharathi AV et al. (2009) Refinement and validation of an FFQ developed to estimate macroand micronutrient intakes in a south Indian population. Public Health Nutr 12, 12-18.

18. Finucane MM, Stevens GA, Cowan MJ et al. (2011) National, regional, and global trends in body-mass index since 1980: systematic analysis of health examination surveys and epidemiological studies with 960 countryyears and 9.1 million participants. Lancet 377, 557-567.

19. Muller-Nordhorn J, Binting S, Roll S et al. (2008) An update on regional variation in cardiovascular mortality within Europe. Eur Heart J 29, 1316-1326.

20. Redon J, Olsen MH, Cooper RS et al. (2011) Stroke mortality and trends from 1990 to 2006 in 39 countries from Europe and Central Asia: implications for control of high blood pressure. Eur Heart J 32, 1424-1431.

21. Guerra F, Paccaud F \& Marques-Vidal P (2012) Trends in food availability in Switzerland, 1961-2007. Eur J Clin Nutr 66, 273-275.

22. Zatonski WA, McMichael AJ \& Powles JW (1998) Ecological study of reasons for sharp decline in mortality from ischaemic heart disease in Poland since 1991. BMJ 316, 1047-1051.

23. Morabia A, Bernstein MS, Heritier S et al. (1999) A Swiss population-based assessment of dietary habits before and after the March 1996 'mad cow disease' crisis. Eur J Clin Nutr 53, 158-163.

24. Heitmann BL, Lissner L \& Osler M (2000) Do we eat less fat, or just report so? Int J Obes Relat Metab Disord 24, 435-442.

25. Breslow RA, Subar AF, Patterson BH et al. (1997) Trends in food intake: the 1987 and 1992 National Health Interview Surveys. Nutr Cancer 28, 86-92.

26. Swiss Society of Nutrition (2011) Lipides. Bern: Swiss Society of Nutrition.

27. Cheng G, Libuda L, Karaolis-Danckert N et al. (2010) Trends in dietary carbohydrate quality during puberty from 1988 to 2007: a cause for concern? Br J Nutr 104, 1375-1383.

28. Skatrud-Mickelson M, Adachi-Mejia AM \& Sutherland LA (2011) Tween sex differences in snacking preferences during television viewing. J Am Diet Assoc 111, 1385-1390.

29. Laurent-Jaccard A, de Matteis L, Hofstetter JR et al. (1994) Are food preferences affected by body mass index, age, sex or tobacco? Schweiz Med Wochenschr 124, 2039-2041.
30. Malik VS \& Hu FB (2012) Sweeteners and risk of obesity and type 2 diabetes: the role of sugar-sweetened beverages. Curr Diab Rep (Epublication ahead of print version).

31. Arnett DK, Xiong B, McGovern PG et al. (2000) Secular trends in dietary macronutrient intake in Minneapolis-St. Paul, Minnesota, 1980-1992. Am J Epidemiol 152, 868-873.

32. Swiss Federal Office for Agriculture (2011) Rapport Agricole 2011 , p. 284. Bern: Swiss Federal Office for Agriculture.

33. Etter JF \& Gmel G (2011) Paradoxical changes in alcohol consumption and CAGE ratings between 1996 and 2006 in the general population of Geneva. Alcohol Alcohol 46, 128-132.

34. Régie Fédérale des alcools (2009) L'alcool en chiffres 2009 [Federal Office for Finances, editor]. Bern: Régie Fédérale des alcools.

35. Swiss Federal Office for Agriculture (2011) L'année viticole 2009/das Weinjahr 2009 [Federal Department of Economy, editor]. Bern: Swiss Federal Office for Agriculture.

36. Michaud PA, Berchtold A, Jeannin A et al. (2006) Secular trends in legal and illegal substance use among 16 to 20 year old adolescents in Switzerland. Swiss Med Wkly 136, 318-326.

37. Producteurs Swisse du Lait (date not available) Grandes tendances. Marché du lait. http://www.swissmilk.ch/fr/ producteurs-de-lait/marche-du-lait/faits-et-chiffres/graphiquesillustrations/grandes-tendances.html (assessed April 2012).

38. Filip RS \& Zagorski J (2005) Osteoporosis risk factors in rural and urban women from the Lublin Region of Poland. Ann Agric Environ Med 12, 21-26.

39. Minaker LM, McCargar L, Lambraki I et al. (2006) School region socio-economic status and geographic locale is associated with food behaviour of Ontario and Alberta adolescents. Can J Public Health 97, 357-361.

40. Sloutskis D, Bernstein M, Burnand B et al. (1995) Consumption of calcium-rich food in the adult population of Frenchspeaking Switzerland and of Tessin. Soz Praventivmed 40, 201-208.

41. Hess SY, Zimmermann MB, Brogli S et al. (2001) A national survey of iron and folate status in pregnant women in Switzerland. Int J Vitam Nutr Res 71, 268-273.

42. World Health Organization (2008) Worldwide Prevalence of Anaemia 1993-2005. WHO Global Database on Anaemia [B de Benoist, E McLean, I Egli et al., editors]. Geneva: WHO.

43. Marques-Vidal P, Ross A, Wynn E et al. (2011) Reproducibility and relative validity of a food-frequency questionnaire for French-speaking Swiss adults. Food Nutr Res 2011, 55, doi: 10.3402/fnr.v55i0.5905.

44. Cook A, Pryer J \& Shetty P (2000) The problem of accuracy in dietary surveys. Analysis of the over 65 UK National Diet and Nutrition Survey. J Epidemiol Community Health 54, 611-616. 